\title{
Transhydrogenation of propyne with butane over a vanadia/ $\theta$-alumina catalyst
}

\author{
Fiona Wigzell • Sreekala Rugmini • \\ S. David Jackson
}

Received: 6 January 2015 / Accepted: 18 February 2015/Published online: 5 May 2015

(c) The Author(s) 2015. This article is published with open access at Springerlink.com

\begin{abstract}
The transhydrogenation of propyne and butane was studied over a $1 \% \mathrm{VO}_{x}$ /alumina catalyst at $873 \mathrm{~K}$. In the absence of the vanadia, the alumina support was active for cracking and alkylation. However, the addition of the vanadia reduced the propensity for both cracking and alkylation and added dehydrogenation activity. When propyne and butane were co-fed over the catalyst there was a synergistic effect resulting in an increased conversion of propyne ( $81 \mathrm{cf} .26 \%$ when fed alone); however, much of this increased conversion was converted to carbon deposited on the catalyst. Transhydrogenation of propyne to propene was detected with an enhanced yield of propene when the propane/butane mix was passed over the catalyst. Taking a yield based on propyne fed then the yield of propene increased from 1.2 to $5.0 \%$. The conversion of butane to value-added products was also enhanced with all the butane converted accounted for in the production of 1-butene, trans-2-butene, iso-butane and iso-butene.
\end{abstract}

Keywords Transhydrogenation - Butane - Propyne · Vanadia

\section{Introduction}

Dehydrogenation is an industrially significant process, providing a direct route for the conversions of alkanes into their corresponding alkenes [1]. However, direct dehydrogenation of alkanes is an endothermic reaction and conversion is limited by a thermodynamic equilibrium. Hence

F. Wigzell · S. Rugmini · S. D. Jackson $(\bowtie)$

Department of Chemistry, WestCHEM, University of Glasgow,

Glasgow G12 8QQ, Scotland, UK

e-mail: david.jackson@glasgow.ac.uk high temperatures are required, especially for lighter chain alkanes, to produce reasonable yields of alkenes; however, this results in side reactions such as thermal cracking and coking leading to catalyst deactivation. Therefore, alternative ways for the production of alkenes are always being sought. A significant amount of research has considered oxidative dehydrogenation, which could potentially deliver a system that is not restricted by the equilibrium limitations of direct dehydrogenation ([2] and references therein). A second route that also has the potential to remove the equilibrium limitation is transhydrogenation. This process brings together dehydrogenation and hydrogenation and has the advantage of converting two lower value products into two higher value products. Some examples of transhydrogenation used hydrogen donors such as propane, butane, or 2-methyl propane and a mono-alkene such as ethene as the acceptor [3, 4]. Hence there was no overall increase in alkene yield, although a more valuable alkene had been produced. However, later patents [5, 6] revealed the benefit that two low value molecules can be converted into two higher value-added molecules potentially under milder conditions if the hydrogen donor is an alkane while the hydrogen acceptor is an alkyne or alkadiene. As well as this, it was found that an advantage of transhydrogenation is that part of the heat required for the dehydrogenation, in this case around $50 \%$, was in effect provided by the exothermic hydrogenation of the hydrogen acceptor.

Despite having patent activity as far back as the 1960s, transhydrogenation is still a reaction where little published research is available. A recent paper [7] on the transhydrogenation of propyne and propane to propene, over potassium-doped chromia/alumina catalysts showed by use of isotopic labelling, that for the reaction, full dehydrogenation of the propane to propene was required. At temperatures of $823 \mathrm{~K}$ transhydrogenation was observed and 
by $873 \mathrm{~K}$ the propene being produced was $80 \%$ of the C-3 stream. However, secondary reactions, for example, the formation of methane or carbon led to a lower yield of propene being produced.

In this paper, we report on the suitability of a vanadia/ $\theta$ alumina catalyst for transhydrogenation of butane and propyne to produce butenes and propene. Previous studies had shown that $\gamma$-alumina was unstable as a support for vanadia under these reaction conditions [8], hence $\theta$-alumina was chosen as the support due to its combination of high thermal stability and high surface area. The catalyst system has been shown to have dehydrogenation activity [9] and at a $1 \%$ loading use at elevated temperatures has been shown to be stable $[9,10]$.

\section{Experimental}

\section{Catalyst preparation}

The catalyst was prepared by incipient wetness impregnation using a $\theta$-alumina support. Before impregnation, the alumina was pre-dried at $353 \mathrm{~K}$ overnight. Aqueous $\mathrm{NH}_{4} \mathrm{VO}_{3}(99+\%$, Aldrich) solution was used to prepare the catalyst with a $1 \%$ $\mathrm{w} / \mathrm{w} \mathrm{V}$ loading. The $\theta$-alumina support $\left(1 / 20^{\prime \prime}\right.$ trilobes, surface area $=101 \mathrm{~m}^{2} \mathrm{~g}^{-1}$, pore volume $=0.60 \mathrm{ml} \mathrm{g}^{-1}$ ) was supplied by Johnson Matthey, UK. After impregnation, the samples were mixed thoroughly using a rotavap for $2 \mathrm{~h}$ at $350 \mathrm{~K}$ and dried by purging with air at $393 \mathrm{~K}$ overnight. Finally, the samples were calcined at $823 \mathrm{~K}$ for $6 \mathrm{~h}$. After calcination the catalyst was ground with a mortar and pestle and sieved to a uniform particle size of $250-425 \mu \mathrm{m}$.

\section{Transhydrogenation activity evaluation}

The activity and selectivity of each catalyst was determined using a fixed-bed, continuous-flow, reactor. The catalyst $\left(0.25 \mathrm{~cm}^{3}\right)$ was reduced in pure hydrogen $\left(40 \mathrm{~cm}^{3} \mathrm{~min}^{-1}\right)$ for $1 \mathrm{~h}$ at $873 \mathrm{~K}$. The flow was switched to argon and the system purged for $30 \mathrm{~min}$. After reduction was complete, the reactant gas, either propyne (Aldrich $98 \%$ ) or propyne-butane mixture (10\% butane, $10 \%$ propyne, helium make up, BOC) was introduced to the reactor at $\sim 60 \mathrm{ml} \mathrm{min}^{-1}$; in all cases the reaction temperature was $873 \mathrm{~K}$. The reaction products were analysed by online gas chromatography (Agilent 6890 series, FID detector) fitted with a $50 \mathrm{~m}$ Varian chrompack capillary column. The reaction was carried out over a 2-h period with samples taken after 10 and $25 \mathrm{~min}$ for propyne and 10,25 and $45 \mathrm{~min}$ for propyne-butane mixture. Regeneration of the catalysts was carried out using $2 \% \mathrm{O}_{2} / \mathrm{Ar}$. After a dehydrogenation reaction, the catalyst was purged with argon at $873 \mathrm{~K}$ for $0.5 \mathrm{~h}$ to remove adsorbed reactant/products from the catalyst surface. Then, the catalyst was cooled to room temperature in a flow of argon. Once at room temperature the gas flow was switched to $2 \% \mathrm{O}_{2} / \mathrm{Ar}$ and the catalysts heated to $873 \mathrm{~K}$ with a programmed heating rate of $10^{\circ} \mathrm{min}^{-1}$. The temperature was maintained at $873 \mathrm{~K}$ until regeneration was complete. The total process was monitored by online mass spectrometry (ESS). The conversion for any given feed was calculated as (feed converted)/(feed fed), while the yield was based on a carbon equivalency, so for all feeds the yield $=($ carbon in product molecule $) /(-$ carbon fed).

\section{Results}

The alumina support was subjected to propyne, butane and a propyne/butane mix to determine its efficacy in the various reactions. The results are shown in Table 1. To investigate the carbon deposited on the surface of the alumina, the support was subjected to a TPO. When the gas flow was switched to $2 \%$ oxygen/argon at room temperature desorption from the catalyst of various species was observed. Such behaviour had been observed before for butane over alumina [9]. The results for Table 1 . Conversion and selectivity for reaction of butane, propyne and propyne/butane mix over alumina. Propyne and the propyne/butane mix are shown in Figs. 1 and 2. Clearly there are reactants and products present on the surface of the alumina and that these change when the gas phase reaction mix changes. After these species have desorbed the catalyst was heated and a standard TPO measured. The TPO for propyne and the propyne/butane mix are shown in Figs. 3 and 4.

Propyne, butane and a propyne:butane mix were passed over the $1 \% \mathrm{VO}_{x} /$ alumina catalyst at $873 \mathrm{~K}$. The results are shown in Table 2. The catalysts were subjected to a TPO after use. When the gas flow was switched to $2 \%$ oxygen/argon at room temperature desorption from the catalyst of various species was observed. The results for the propyne/butane mix are shown in Figs. 5 and 6.

\section{Discussion}

The catalyst used in this study has been thoroughly characterised by a range of techniques including Raman spectroscopy, UV-Vis spectroscopy, temperature-programmed reduction and oxygen chemisorption [9-12]. Briefly, the alumina support is covered principally in isolated $\mathrm{VO}_{x}$ species at a coverage of $1.1 \mathrm{~V} \mathrm{~nm}^{-2}$. On treatment with hydrogen at $873 \mathrm{~K}$ these species reduce to give a surface $\mathrm{VO}_{x}$ species with an oxidation state of $\sim 4$ and the loss of one oxygen atom per vanadium atom. Under reducing conditions and those of butane 
Table 1 Conversion and selectivity for reaction of butane, propyne and propyne/butane mix over alumina

\begin{tabular}{|c|c|c|c|c|c|c|c|c|c|c|c|c|c|c|c|}
\hline \multirow[t]{2}{*}{ TOS } & \multirow{2}{*}{$\begin{array}{l}\text { Conv. } \\
(\%)\end{array}$} & \multicolumn{14}{|c|}{ Yield (\%) } \\
\hline & & $\begin{array}{l}n- \\
\text { Butane }\end{array}$ & $\begin{array}{l}\text { Conv. } \\
\text { Propyne } \\
(\%)\end{array}$ & $\begin{array}{l}\text { Conv. } \\
\text { Butane } \\
(\%)\end{array}$ & $\begin{array}{l}\text { trans- } \\
2- \\
\text { Butene }\end{array}$ & $\begin{array}{l}\text { 1- } \\
\text { Butene }\end{array}$ & $\begin{array}{l}\text { cis-2- } \\
\text { Butene }\end{array}$ & $\begin{array}{l}\text { iso- } \\
\text { Butane }\end{array}$ & $\begin{array}{l}1,3- \\
\text { Butadiene }\end{array}$ & $\begin{array}{l}\text { iso- } \\
\text { Butene }\end{array}$ & Methane & Ethane & Propane & Ethene & Propene \\
\hline \multicolumn{16}{|c|}{ Propyne } \\
\hline 10 & 63.0 & 4.6 & & & 0.2 & 0.2 & 0.2 & & 0 & 0.5 & 0.6 & 0.2 & 0.1 & 0.3 & 3.2 \\
\hline 25 & 13.9 & 0.9 & & & 0.1 & 0 & 0.1 & & 0 & 0 & 0.0 & 0.0 & 0 & 0.0 & 0.2 \\
\hline \multicolumn{16}{|c|}{ Butane } \\
\hline 10 & 5.8 & & & & 0.6 & 0.7 & 0 & & 0 & 0 & 0.7 & 1.0 & 1.3 & 2.2 & 8.9 \\
\hline 25 & 6.1 & & & & 0.6 & 0.7 & 0 & & 0 & 0 & 0.7 & 1.0 & 0 & 2.5 & 9.5 \\
\hline \multicolumn{16}{|c|}{ Propyne/butane } \\
\hline 10 & & & 87.0 & 1.3 & 0.2 & 0 & 0 & 0.8 & 0 & 2.0 & 0.2 & 0.1 & 0 & 0.2 & 1.0 \\
\hline 25 & & & 43.5 & 7.0 & 0 & 0 & 0 & 3.6 & 0 & 0.3 & 0.1 & 0 & 0 & 0.1 & 0.5 \\
\hline
\end{tabular}

Fig. 1 Desorption of surface species from alumina at room temperature in $\mathrm{O}_{2} / \mathrm{Ar}$ after reaction with propyne at $873 \mathrm{~K}$

Fig. 2 Desorption of surface species from alumina at room temperature in $\mathrm{O}_{2} / \mathrm{Ar}$ after reaction with a propyne/butane $\operatorname{mix}$ at $873 \mathrm{~K}$
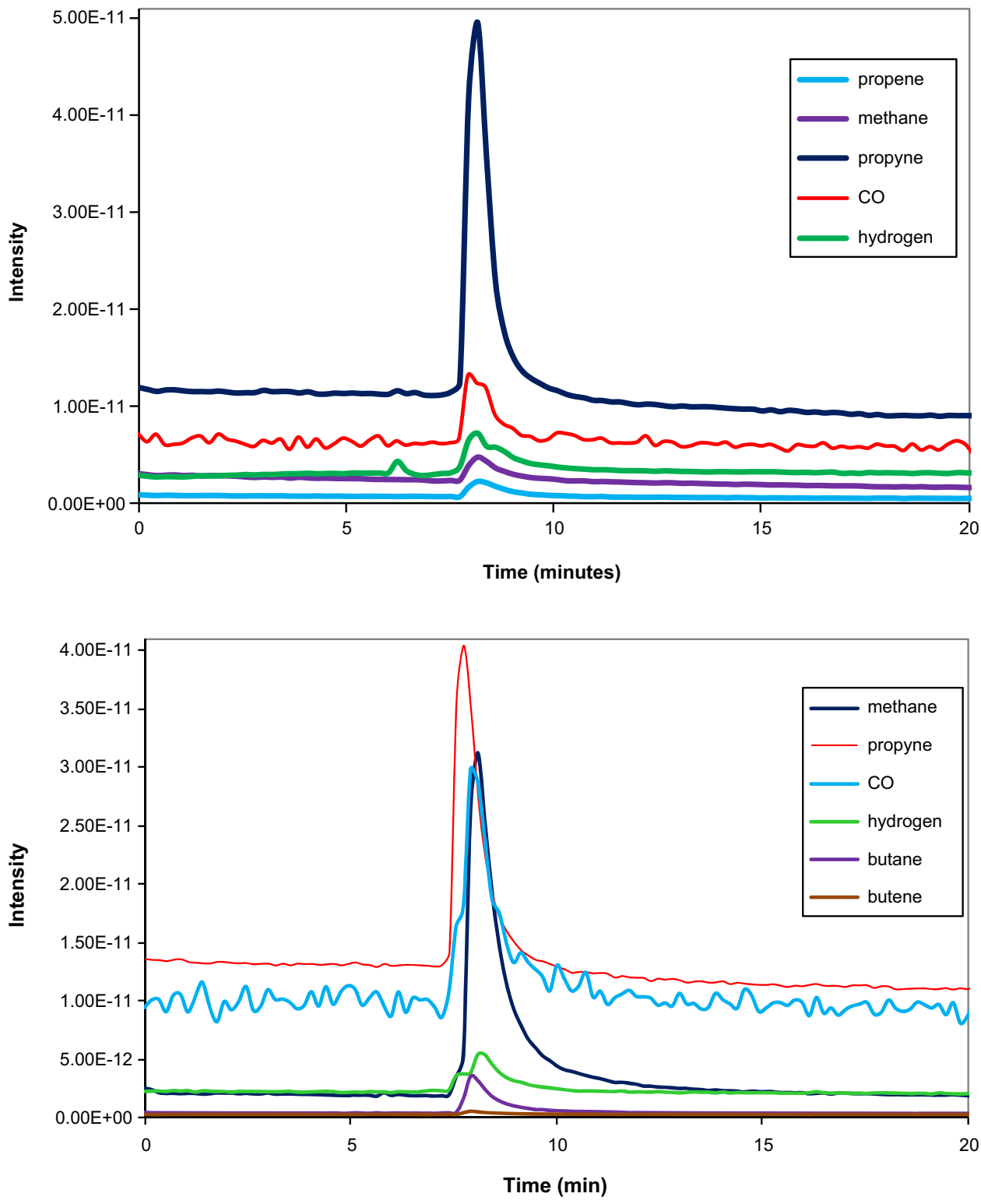
Fig. 3 TPO of post-reaction alumina support after propyne reaction at $873 \mathrm{~K}$
Fig. 4 TPO of post-reaction alumina support after butane/ propyne reaction at $873 \mathrm{~K}$

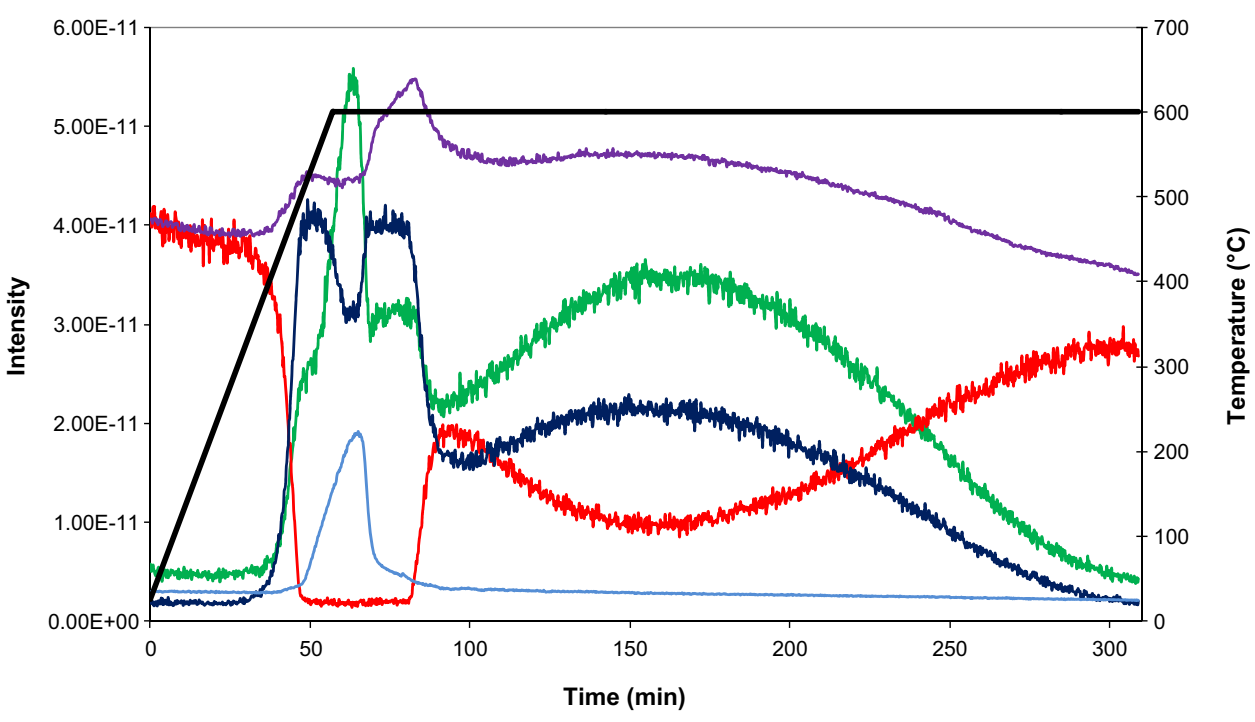

— $\mathrm{CO}$ - oxygen — carbon dioxide — hydrogen — water - Temperature

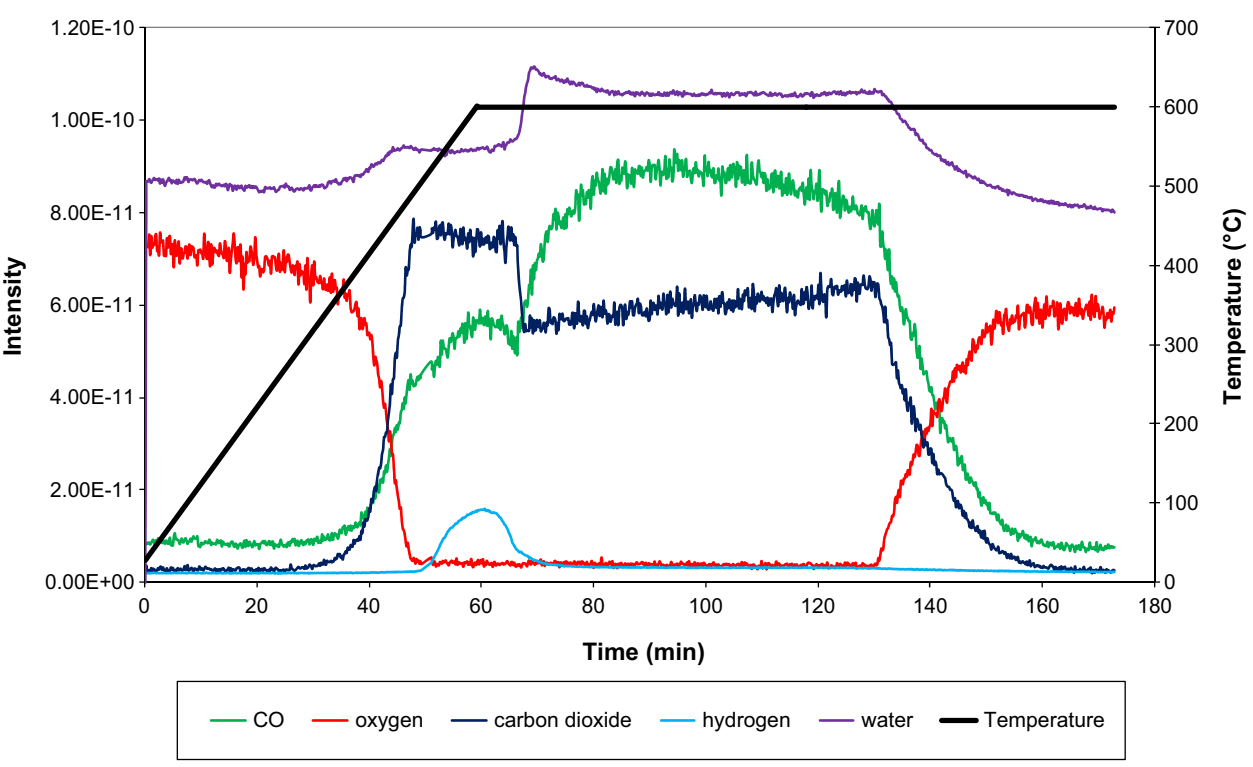

dehydrogenation $(873 \mathrm{~K})$ it has been shown that both the support and the $\mathrm{VO}_{x}$ species are stable [10]; however, changes can occur to the $\mathrm{VO}_{x}$ species and the support under cycling of the catalyst between reducing and oxidising conditions $[10,13]$.

The alumina support shows classic cracking activity with ethene and propene being the highest yield products when butane is the feedstock. When propyne is the feed similar chemistry is observed but as well as propene, $n$ butane is also produced and indeed has the highest yield. Therefore, as well as molecular fracture (cracking) the support is also catalysing alkylation, adding on a $\mathrm{CH}_{3}$ unit to the $\mathrm{C}-3$ species giving both $n$-butane and iso-butene. This behaviour is much more pronounced when propyne is the feed due the more reactive nature of the molecule and is reflected in the conversions, $63 \%$ for propyne c.f. $5.8 \%$ for butane. Such behaviour has been well known for over 60 years [14-16] as is the formation of higher molecular weight by-products leading to catalyst coking. Indeed with propyne feed there is a $78 \%$ loss in catalytic activity in 15 min on stream (Table 1). The same is not true when butane is fed where no loss in activity is observed. This difference in behaviour is also observed in the TPO profiles.

When an oxygen containing gas is passed over the alumina at room temperature, a small amount of material is desorbed from the support. For butane this behaviour has been reported previously [9] with the main species desorbed being butane. A similar behaviour pattern is observed with propyne where the main species desorbed at 
Table 2 Conversion and selectivity for reaction of butane, propyne and propyne/butane mix over $1 \% \mathrm{VO}_{x} /$ alumina

\begin{tabular}{|c|c|c|c|c|c|c|c|c|c|c|c|c|c|c|c|}
\hline \multirow[t]{2}{*}{ TOS } & \multirow{2}{*}{$\begin{array}{l}\text { Conv. } \\
(\%)\end{array}$} & \multicolumn{14}{|c|}{ Yield (\%) } \\
\hline & & $\begin{array}{l}n- \\
\text { Butane }\end{array}$ & $\begin{array}{l}\text { Conv. } \\
\text { Propyne } \\
(\%)\end{array}$ & $\begin{array}{l}\text { Conv. } \\
\text { Butane } \\
(\%)\end{array}$ & $\begin{array}{l}\text { trans- } \\
2- \\
\text { Butene }\end{array}$ & $\begin{array}{l}1- \\
\text { Butene }\end{array}$ & $\begin{array}{l}\text { cis-2- } \\
\text { Butene }\end{array}$ & $\begin{array}{l}\text { iso- } \\
\text { Butane }\end{array}$ & $\begin{array}{l}1,3- \\
\text { Butadiene }\end{array}$ & $\begin{array}{l}\text { iso- } \\
\text { Butene }\end{array}$ & Methane & Ethane & Propane & Ethene & Propene \\
\hline \multicolumn{16}{|c|}{ Propyne } \\
\hline 10 & 26 & 2.0 & & & 0.1 & 0.1 & 0.2 & & 0.1 & 0 & 0.3 & 0.1 & 0.1 & 0.1 & 1.2 \\
\hline 25 & 9 & 0.3 & & & 0.0 & 0 & 0 & & 0.0 & 0 & 0.0 & 0 & 0 & 0.0 & 0.0 \\
\hline \multicolumn{16}{|c|}{ Butane } \\
\hline 10 & 6 & & & & 0.5 & 0.6 & 0.4 & & 0 & 0 & 0.0 & 0.1 & 0.1 & 0.1 & 0.4 \\
\hline 25 & 5 & & & & 0.5 & 0.5 & 0.4 & & 0 & 0 & 0.0 & 0.1 & 0.1 & 0.1 & 0.4 \\
\hline \multicolumn{16}{|c|}{ Propyne/butane } \\
\hline 10 & & & 81 & 7 & 0.2 & 0.3 & 0 & 1.3 & 0 & 1.2 & 0.2 & 0.1 & 0 & 0.1 & 3.1 \\
\hline 25 & & & 40 & 10 & 0 & 0 & 0 & 3.8 & 0 & 0.3 & 0.1 & 0 & 0 & 0.1 & 0.3 \\
\hline 45 & & & 23 & 6 & 0 & 0 & 0 & 1.8 & 0 & 0.2 & 0.1 & 0 & 0 & 0 & 0.2 \\
\hline
\end{tabular}

Fig. 5 Desorption of surface species from $1 \% \mathrm{VO}_{x} /$ alumina at room temperature in $\mathrm{O}_{2} / \mathrm{Ar}$ after reaction with a $2: 1$ propyne/butane mix at $873 \mathrm{~K}$

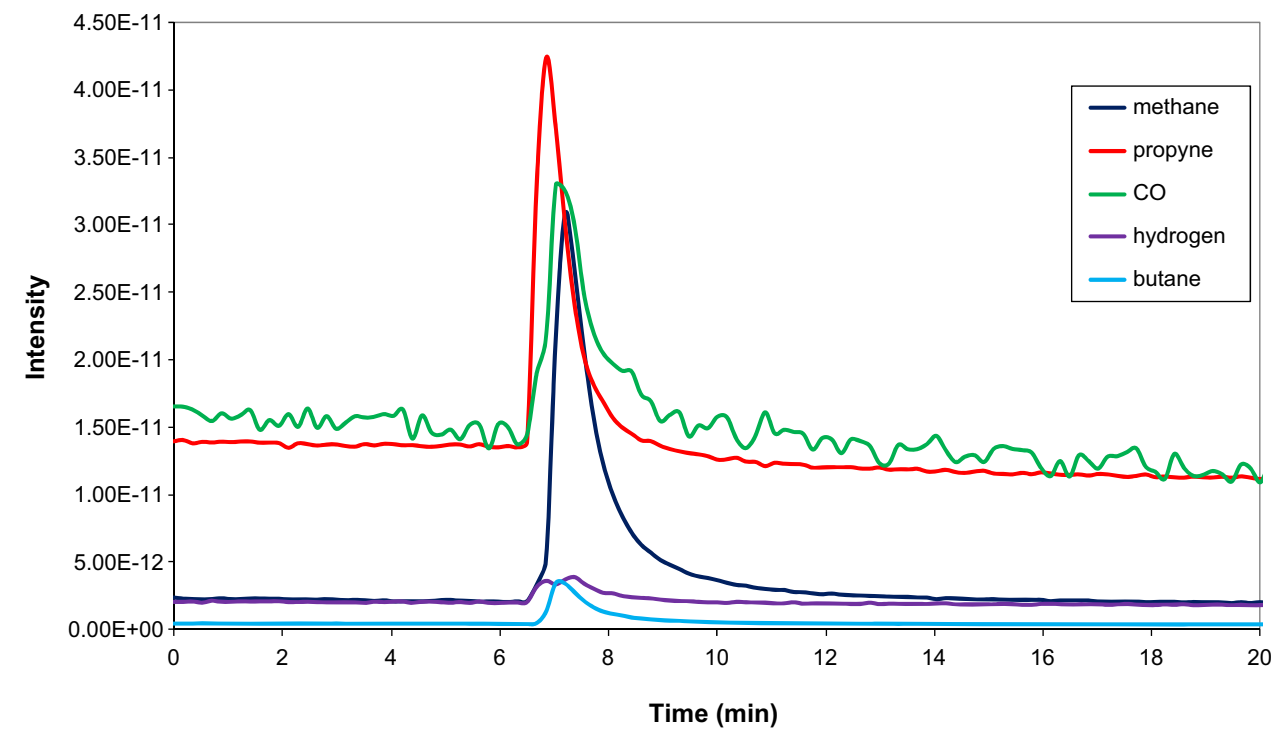

room temperature is propyne. The subsequent TPO, however, is less similar. With butane there is little carbon deposition and there is low level carbon dioxide evolution between 423 and $873 \mathrm{~K}$ [9]. The TPO of the alumina after propyne reaction at $873 \mathrm{~K}$ reveals a much more significant amount of carbon laydown with removal of all the oxygen in the feed and the production of carbon monoxide and hydrogen as the main products at around $873 \mathrm{~K}$ rather than carbon dioxide and water. Also the carbon is of a much more recalcitrant type needing prolonged heating at high temperature to be removed. This is consistent with alkylation occurring over the alumina when high molecular weight aromatic species can be formed [15, 16].

When propyne and butane are passed over the alumina support the conversion of propyne is enhanced, whereas initially the conversion of butane is depressed. The main products are iso-butane, iso-butene and propene. Although the main reactions are still cracking and alkylation, it is also clear that there is reaction between the two reactants. The production of iso-butane is significant and was not seen with either reactant separately. Similarly, the extent of deactivation as seen by the reduction in the propyne conversion is much less marked than when propyne was fed individually. This is surprising as the TPO reveals a far greater carbon deposition; however, there is some evidence that the carbon is in a slightly more hydrogenated form.

When the reactions are carried out over the catalyst there is a change in behaviour. When propyne is passed over the $1 \% \mathrm{VO}_{x}$ /alumina the conversion is reduced and the product distribution is changed, for example no isobutene is formed. Overall there is much less cracking and alkylation. This can be explained by the interaction of the vanadia species with the alumina and removing some of the active sites for cracking and alkylation. When the 
Fig. 6 TPO from $1 \% \mathrm{VO}_{x} /$ alumina $\mathrm{O}_{2} / \mathrm{Ar}$ after reaction with a propyne/butane mix at $873 \mathrm{~K}$

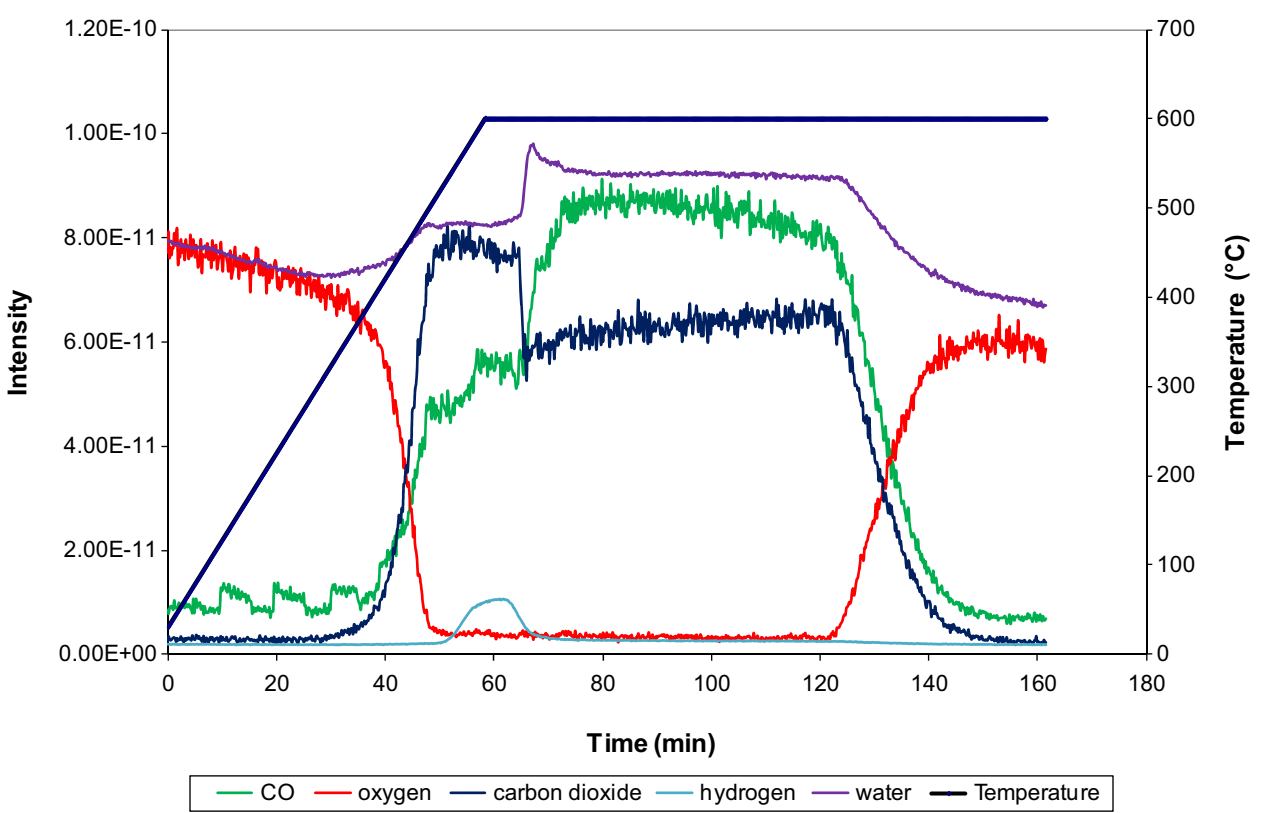

interaction of the vanadia species with the alumina was studied by FTIR [10], it was found that the $\mathrm{VO}_{x}$ reacted with the most basic hydroxyl groups on the alumina surface. These hydroxyl groups will typically be the most active for cracking and alkylation, hence their removal is in keeping with the reduced activity for these reactions. When butane is passed over the catalyst we observe dehydrogenation with all three butene isomers produced. The extent of cracking is much reduced with, for example propene yield reducing from $8.9 \%$ over the alumina to $0.4 \%$ over the $1 \% \mathrm{VO}_{x}$ /alumina. This is as expected for the reaction of butane as the vanadia site is much more selective to dehydrogenation [9-11].

When both reactants are passed over the catalyst a unique product distribution is observed. Firstly, no cis-2-butene is formed, even though both reactants produce this product when passed over the catalyst individually; secondly, both iso-butane and iso-butene are formed even though neither reactant produces these products when passed over the catalyst individually. Thirdly, an enhanced initial yield of propene is observed. The absence of cis-2-butene is a slightly odd result, although the primary product of butane dehydrogenation is 1-butene [9] there is rapid isomerisation and the production of both trans- and cis-2-butene. Note that the yield of 1-butene and trans-2-butene is very similar to that found in the absence of propyne if we assume that the butenes are only formed from butane $(0.7 \%$ 1-butene, $0.5 \%$ trans-2-butene from the mixed feed cf. $0.6 \%$ 1-butene, $0.5 \%$ trans-2-butene from the butane feed). This implies that either the 1-butene isomers to trans-2-butene first prior to isomerisation to cis-2-butene, as this would allow a situation where no $\mathrm{cis}$-2-butene was detected, or $\mathrm{cis}$ 2-butene is formed but reacts in the alkylation reaction to form iso-butane (ene). Interestingly, assuming that a butane molecule must be used to form either iso-butane or isobutene then all of the butane conversion can be accounted for in the production of 1-butene, trans-2-butene, iso-butane and iso-butene. However, after 25 min time on stream the butane conversion remains approximately the same yet no dehydrogenation products are observed. The likely reason for this is carbon deposition from the propyne poisoning the dehydrogenation activity. It has been shown in previous studies of alkane dehydrogenation $[9,17]$ that the materials desorbed at room temperature in an oxidising gas are responsible for the major loss in activity for vanadia-based catalysts. In this case it can be seen from Fig. 5 that propyne, methane and carbon monoxide are the principal gases desorbed and these can all be traced back to propyne. The transhydrogenation activity is also lost when the main dehydrogenation activity is lost. This can be seen from the drop in propene yield. Note that the amount of iso-butane and iso-butene formed match the butane conversion in agreement with the TPO that butane contributes very little to the carbon deposition.

\section{Conclusions}

We have examined the transhydrogenation of propyne and butane over a $1 \% \mathrm{VO}_{x} /$ alumina catalyst at $873 \mathrm{~K}$. In the absence of the vanadia, the alumina support was active for cracking and alkylation. However, the addition of the vanadia reduced the propensity for both cracking and alkylation and added dehydrogenation activity. When propyne and butane were co-fed over the catalyst there was a synergistic effect resulting in a far higher conversion of 
propyne ( 81 cf. $26 \%$ when fed alone); however, much of this increased conversion was converted to carbon deposited on the catalyst. The behaviour is similar to that observed when propyne and propane were transhydrogenated over a $\mathrm{CrO}_{x}$ /alumina catalyst when there was catastrophic loss of propane to the surface [18]. Transhydrogenation of propyne to propene was detected with an enhanced yield of propene when the propane/butane mix was passed over the catalyst. Taking a yield based on propyne fed then the yield of propene increased from $1.2-5.0 \%$. The conversion of butane to value-added products is also enhanced with all the butane converted accounted for in the production of 1-butene, trans-2butene, iso-butane and iso-butene.

Open Access This article is distributed under the terms of the Creative Commons Attribution 4.0 International License (http:// creativecommons.org/licenses/by/4.0/), which permits unrestricted use, distribution, and reproduction in any medium, provided you give appropriate credit to the original author(s) and the source, provide a link to the Creative Commons license, and indicate if changes were made.

\section{References}

1. Bhasin MM, McCain JH, Vora BV, Imai T, Pujado PR (2001) Appl Catal A 221:397-419
2. Centi G, Carvani F, Trifiro F (2001) Selective oxidation by heterogeneous catalysis. Kluwer Academic Plenum Press, New York

3. Aldridge CL, Rigney JA (1964) Process for forming olefins by hydrogen transfer; assigned to Exxon. US Patent 3267170

4. Gough A, Turner S (1991) Transhydrogenation; assigned to IFP. US Patent 5585530

5. Parris D, Tonner SP (1985) Chemical process; assigned to ICI Australia Ltd. US Patent 4684755

6. (2012) Method of producing olefin through transhydrogenation; assigned to Sumitomo Chemical Co. Japanese Patent 2013173706

7. Jackson SD, Matheson IM, Webb G (2005) Appl Catal 289:16-21

8. Jackson SD, Lennon D, Webb G, Willis J (2001) Stud Surf Sci Catal 139:271-278

9. Jackson SD, Rugmini S (2007) J Catal 251:59-68

10. McGregor J, Huang Z, Shiko G, Gladden LF, Stein RS, Duer MJ, Wu Z, Stair PC, Rugmini S, Jackson SD (2009) Catal Today 142:143-151

11. Wu Z, Kim HS, Stair PC, Rugmini S, Jackson SD (2005) J Phys Chem B 109:2793-2800

12. Jackson SD, Rugmini S, Stair PC, Wu Z (2006) Chem Eng J 120:127-132

13. Jackson SD, Lennon D, Webb G, Willis J (2001) Stud Surf Sci Catal 139:271-278

14. Greensfelder BS, Voge HH, Good GM (1949) Ind Eng Chem Res 41:2573-2584

15. Guisnet M, Gnep NS (1996) Appl Catal A 146:33-64

16. Sterte J, Otterstedt J-E (1988) Appl Catal 38:131-142

17. Edussuriya M, Jackson SD, Rugmini S (2010) Curr Top Catal 9:15-24

18. Jackson SD, Matheson IM, Webb G (2004) Preprints. Div Pet Chem ACS 49:50-53 